\title{
Early vitrectomy for severe eye injuries
}

\author{
Ferenc Kuhn $\mathbb{I}^{1,2} \cdot$ Robert Morris $^{2}$
}

Received: 2 September 2020 / Revised: 9 November 2020 / Accepted: 9 November 2020 / Published online: 24 November 2020

(c) The Royal College of Ophthalmologists 2020

Trauma remains a major source of vision loss, especially in developing countries. The prognosis is determined by the following variables: the acute damage inflicted by the responsible object; the expertise and experience of the treatment team ("what to do"); the timing of the intervention/s ("when to do it"); and the body's scar-formation reaction to both injury and surgery.

Of these, the easiest to control is the timing of the reconstructive surgery. Before the vitrectomy era, intraocular reconstruction (unavailable) and its timing (hence irrelevant) were obviously mute points. Since vitreoretinal surgery was introduced, the "what" and the "when" have been extensively debated to identify the optimal approach.

The greatest influence on the question of timing has been a series of publications, based on experimental studies, in the late 1970s by Cleary and Ryan [1-3]. As a result, the "mainstream" option regarding the timing of the intraocular reconstruction, according to most literature reports, is a staged approach with wound closure on day 1 , followed by vitreoretinal surgery in the second half of the 2nd week [46]. In real life, however, the authors' extensive international experience shows that rather than 10-14 days, the delay is too often several weeks.

In addition to data from animal experiments, clinical arguments can also be made in favor of delaying the vitrectomy. First, the infrastructure for a primary comprehensive intraocular reconstruction (wound closure plus vitreoretinal surgery, and everything in between) is not in place: the surgeon inexperienced, the operating-room staff untrained, certain equipment/materials unavailable etc. Second, the surgeon is not willing to face the relatively high risk of an intraoperative choroidal hemorrhage. Third, an

Ferenc Kuhn

fkuhn@mindspring.com

International Society of Ocular Trauma, Jacksonville, FL, USA

2 Helen Keller Foundation for Research and Education, Birmingham, AL, USA unsutured posterior scleral wound may be present and threaten reopening during vitrectomy. Fourth, the surgeon prefers waiting for a spontaneous posterior detachment (PVD), knowing that in these typically young patients a surgical PVD is difficult if not dangerous to attempt. Let's look at these arguments in detail.

If the infrastructure for optimal surgery is unavailable, the decision obviously must be to postpone it. The same is true for a surgeon for whom the risk of choroidal hemorrhage is deemed too high. Conversely, an unsutured posterior scleral wound is only a relative contraindication as such wounds are typically small and quickly begin healing: unless the surgeon mechanically reopens it or the intraocular pressure is too high, the wound will remain closed. The final argument, waiting for a spontaneous PVD, is simply bogus: those surgeons who check the presence of vitreous on the posterior retinal surface using triamcinolone will find the cortical vitreous still adherent even after several weeks postinjury [7], during which time the scarring (proliferative vitreoretinopathy, PVR) has already progressed, causing irreversible damage.

Foregoing the option of primary intraocular reconstruction leaves the surgeon with two options: early vs. delayed vitrectomy, where "early" is defined as within a few days postinjury, and delayed means anything beyond, including the "mainstream" 10-14 days option. Based on what criteria should the surgeon decide?

The main causes of anatomical and functional failure in a severely traumatized eye are scarring, which can lead to corneal opacity, glaucoma, phthisis, and retinal detachment due to PVR. The last one of these is the chief culprit, destroying vision in many eyes that had survived the original insult [8].

The process of PVR is a normal reaction of the human body to intraocular hemorrhage, inflammation, and tissue disorganization. The resulting tractional (tractional/rhegmatogenous) retinal detachment is difficult to treat, and PVR commonly recurs. The prognosis of each successive surgery for PVR is worse than the one before it, making prophylaxis, rather than treatment, the ideal option [7]. 
Preventing PVR development has long been a goal of the vitreoretinal surgeon. An extensive list of drugs has been tested for this purpose, but the vast majority were outright failures. Today, it appears that prolonged methotrexate treatment offers a decent option [9], but more clinical experience is needed to find the most optimal dosing, and the drug must be approved by the relevant national health authorities for intraocular use [10].

There is also a surgical option, prophylactic chorioretinectomy, for eyes with high risk of retinal incarceration into the scleral wound: perforating injuries, ruptures with a postequatorial extension, and intraocular foreign bodies with a deep impact (involving the retinal pigment epithelium/choroid) [11]. Prophylactic chorioretinectomy is a very effective procedure, but it is not applicable in all types of trauma, and PVR can still develop outside the treated area.

This leaves the surgeon with one option, which, again, is the easiest of all: abandoning the traditional timing and not delaying vitrectomy reconstruction beyond the first few days. While 20 gauge vitrectomy with conjunctival dissection may have been a daunting prospect in the recently traumatized, "bloodshot" eye, intraocular reconstruction can now be achieved transconjunctivally, without any surface dissection.

Even in the absence of level-one evidence that early vitrectomy is preferable to a delayed one, common sense should still prevail. It is difficult to organize such a study, given the many unrandomizable variables in complex eye injury cases-but then no randomized clinical trial has shown that parachute-use prevents death after jumping from high-flying aircraft [12] or that lens removal with intraocular lens implantation achieves rapid and comprehensive visual rehabilitation in people with cataract.

Common sense tells us that removing the hemorrhagic vitreous, injured lens, and inflammatory debris, and restoring the intraocular anatomy to as close to normal as possible before the scarring process begins, is preferable to fighting the consequences of actively advancing scar formation. The study by Akincioglu et al., in a large group of patients, indeed found that eyes undergoing vitrectomy in the first 4 postinjury days had significantly better anatomical and functional results than eyes with delayed reconstruction. The benefits of early vitrectomy were demonstrated in a few prior studies [13,14] and have also been confirmed in a more recent, prospective study [15].

Based on these findings, and common sense, we highly recommend vitrectomy within the first 4 days for eyes with a severe injury. It is time to change the proverb "better late than never" to: better early than late.

\section{Compliance with ethical standards}

Conflict of interest The authors declare that they have no conflict of interest.

Publisher's note Springer Nature remains neutral with regard to jurisdictional claims in published maps and institutional affiliations.

\section{References}

1. Cleary PE, Ryan SJ. Method of production and natural history of experimental posterior penetrating eye injury in the rhesus monkey. Am J Ophthalmol. 1979;88:212-20.

2. Cleary PE, Ryan SJ. Histology of wound, vitreous, and retina in experimental posterior penetrating eye injury in the rhesus monkey. Am J Ophthalmol. 1979;88:221-31.

3. Cleary PE, Ryan SJ. Experimental posterior penetrating eye injury in the rabbit. II. Histology of wound, vitreous, and retina. Br J Ophthalmol. 1979;63:312-21.

4. Akesbi J, Adam R, Rodallec T, Barale P-O, Ayello-Scheer S, Labbé A, et al. [Intraocular foreign bodies (IOFB) of the posterior segment: retrospective analysis and management of 57 cases]. J Fr Ophtalmol. 2011;34:634-40.

5. Sandinha MT, Newman W, Wong D, Stappler T. Outcomes of delayed vitrectomy in open-globe injuries in young patients. Retina. 2011;31:1541-4.

6. Feng K, Hu Y, Wang C, et al. Risk factors, anatomical, and visual outcomes of injured eyes with proliferative vitreoretinopathy: eye injury vitrectomy study. Retina. 2013;33:1512-8.

7. Kuhn F, Schrader W. Prophylactic chorioretinectomy for eye injuries with high proliferative-vitreoretinopathy risk. Clin Anat. 2018;31:28-38.

8. Cardillo JA, Stout JT, LaBree L, Azen SP, Omphroy L, Cui JZ, et al. Post-traumatic proliferative vitreoretinopathy. The epidemiologic profile, onset, risk factors, and visual outcome. Ophthalmology. 1997;104:1166-73.

9. Amarnani D, Machuca-Parra AI, Wong LL, Marko CK, Stefater JA, Stryjewski TP, et al. Effect of methotrexate on an in vitro patient-derived model of proliferative vitreoretinopathy. Invest Ophthalmol Vis Sci. 2017;58:3940-9.

10. Denstedt J, Schulz DC, Diaconita V, Sheidow TG. Acupuncture resulting in eye penetration and proliferative vitreoretinopathysurgical and medical management with intraocular methotrexate. Am J Ophthalmol Case Rep. 2020;18:100605.

11. Kuhn F, Mester V, Morris R. A proactive treatment approach for eyes with perforating injury. Klin Monbl Augenheilkd. 2004;221:622-8.

12. Smith GC, Pell JP. Parachute use to prevent death and major trauma related to gravitational challenge: systematic review of randomised controlled trials. BMJ. 2003;327:1459-61.

13. Coleman DJ. Early vitrectomy in the management of the severely traumatized eye. Am J Ophthalmol. 1982;93:543-51.

14. Lemmen KD, Heimann K. [Early vitrectomy with primary silicone oil injection in very severely injured eyes]. Klin Monbl Augenheilkd. 1988;193:594-601.

15. He Y, Zhang L, Wang F, Zhu M, Wang Y, Liu Y. Timing influence on outcomes of vitrectomy for open-globe injury: A prospective randomized comparative study. Retina. 2020;40:725-34. 